\title{
Factors Related to Medication Adherence in Schizophrenia in an Outpatient Setting: A Cross Sectional Study Conducted in Bandung, West Java, Indonesia
}

\author{
Heni Purnama ${ }^{1}$, Anchaleeporn Amatayakul $^{2}$, Sonthaya Maneerat ${ }^{3}$
}

\begin{abstract}
Background: Medication adherence is important to help prevent relapse for patients with schizophrenia who need long term care. Purpose: To determine factors related to medication adherence among patients with schizophrenia in Bandung, West Java, Indonesia. Method: A cross-sectional study was conducted at the outpatient department of the West Java Province Mental Hospital in Bandung, West Java, Indonesia. Individuals were assessed using the Bahasa versions of Medication Adherence Rating Scale (MARS), Liverpool University Neuroleptic Side-Effect Rating Scale (LUNSERS), and Symptom Severity Scale of the Diagnostic and Statistical Manual of Mental Disorder $5^{\text {th }}$ edition (SS-DSM5) instruments. Bivariate analysis was applied to determine the factors related to medication adherence. Result: A total of 88 patients with schizophrenia were enrolled. The prevalence of medication adherence was $64.8 \%$. By using Chi-square test, the results revealed that factors significantly associated with medication adherence were medication side effects $\left(\chi^{2}=8.417, p\right.$ $<.01)$, and severity of symptoms $\left(\chi^{2}=5.771, p<.05\right)$. Conclusion: The health care providers should provide clear information to patients and caregivers regarding common side effects of antipsychotics. Enhance the ability of caregivers to identify symptoms of schizophrenia in order to improve patients' health status and reduce relapse.
\end{abstract}

\section{Keywords-Medication adherence, schizophrenia, Indonesia}

\section{Introduction}

Schizophrenia is a mental illness characterized by the symptoms of delusions, hallucinations, thought disorder, and cognitive deficits, which frequently follow a chronic illness and is associated with decline in social and occupational functioning [22]. Schizophrenia affecting more than 21 million people worldwide [37]. The prevalence of mental illness such as schizophrenia reached 6.2 million in SouthEast Asia [36].

\section{Heni Purnama}

Kasetsart University

Thailand

\section{Anchaleeporn Amatayakul}

Boromarajonani College of Nursing Nopparat Vajira Thailand

\section{Sonthaya Maneerat}

Boromarajonani College of Nursing Nopparat Vajira Thailand
The Ministry of Health of the Republic of Indonesia (2013) reported that one to two people in a thousand people have suffered from severe mental illness in Indonesia. Schizophrenia has a substantial impact on patients, family, and society. The impact on the individual includes patients social functioning (e.g. occupational performance, functioning in interactions with spouses, parents, children or other relatives), and patients self-care (e.g. personal hygiene, dressing and feeding) [12]. The burden of care for people with schizophrenia has impact on families, resulting in a significant cost for the caregiver as well as for the person with schizophrenia [14].

Antipsychotic medication is one of the important treatments that are effective in reducing psychotic symptoms, preventing psychotic relapses in maintaining therapy and improving psychosocial functioning among patients with schizophrenia [5], [9]. Several studies estimated that the non-adherence rate in patients with schizophrenia was about 50\% [6], [7], [11], [16]. Medication non-adherence had a significantly negative impact on the treatment outcomes [20], and estimated to cause 125,000 deaths annually [1]. The consequences of non-adherence in patients with schizophrenia included greater risk of relapse, hospitalization, longer time to remission, suicide and increased costs to healthcare systems [8], [10], [19], [34].

Medication adherence is a key factor related to the effectiveness of all pharmacological therapies [3]. Patients will be achieve the full benefits of effectiveness of medication if the patients follow prescribed treatment regimens [27]. Furthermore, medication adherence is one best strategies to prevent all those negative impact of nonadherence. According to the World Health Organization (2003), medication adherence is influenced by a considerable number of factors. The World Health Organization (WHO) has categorized factors related to medication adherence in general population into five factors called the Multidimensional Adherence Model (MAM). The five dimensions of the MAM are; (1) Socioeconomic factors; (2) Therapy related factors; (3) Patient related factors; (4) Condition related factors; (5) Health Care System related factors. Several factors such as socioeconomic factors, medication side effects, and severity of symptom could influence medication adherence, however there was still inconsistent reporting of factors related to medication adherence among patient with schizophrenia [22], [23], [31]. 
West Java Province Mental Hospital in West Java province is a tertiary referral hospital in Indonesia. The amount of mental illness patients admitted in the hospital in 2013 was 1,672 and among them 1,235 were diagnosed with schizophrenia. In the outpatient department of this hospital, approximately 1732 patients with schizophrenia were registered in 2014, and among them around 775 patients were in relapse and this was mostly caused by nonadherence to medication [26]. Therefore, it is a challenge for health care provider to promote not only medication adherence but also how to prevent non-adherence by concerning to the factors related to medication adherence.

\section{Method}

A cross-sectional study design was employed and used purposive sampling to recruited 88 participants with schizophrenia at the outpatient department of West Java Province Mental Hospital, Indonesia.

Inclusion criteria were:

- Patients with schizophrenia diagnosed by psychiatrists according to ICD-10

- Aged between 18-59 years old at time of study

- Prescribed at least one antipsychotic drug and who have been receiving treatment for more than one month and up to 5 years as confirmed by a physician and medical report

- Able to read, written and spoken Bahasa Indonesia and willingness to participate.

Patients with unstable condition (depression, mania, and cognitive impairment), neurological illness (e.g. epilepsy, Alzheimer's disease, dementia, stroke, and Parkinson's disease), and patients with substance abuse confirmed by physician and medical report were excluded from the study.

\section{A. Instruments}

Baseline demographic data included area, age, gender, marital status, and employment status. Medication adherence was measured using Medication Adherence Rating Scale (MARS) [31]. The reliability analysis of the MARS was tested using compliance in psychiatric patients. The Cronbach's alpha was 0.75, and the test-retest was assessed after a 2-week interval using parallel-forms Chisquare to test the goodness of fit and was 0.72 for the MARS [31]. The reliability of the MARS in this study was tested using 30 schizophrenia patients, and the result of KR20 was 0.72 . The MARS consists of 10 items, which require yes/no responses. The participants were asked to circle the answer which best describes their behavior or attitude towards their medication during the previous week. A MARS score equal to 3 or above indicates adherence, and non-adherence is defined as scores less than or equal to 2 . A high score reflected a degree of adherence, and a low score reflected a degree of non-adherence.

Medication side effects were measured using the Liverpool University Neuroleptic Side-Effect Rating Scale (LUNSERS) questionnaire. The developers, Day et al.
(1995) reported that the LUNSERS is an efficient, reliable, and valid method of assessing antipsychotic medication side effects that has good concurrent validity against the widelyused side-effect rating scale $(\mathrm{r}=0.828, \mathrm{P}<0.001)$. Internal consistency of the scale was 0.85 and test-retest reliability 0.81 [4]. The reliability of the LUNSERS in this study was tested using 30 schizophrenia patients, and the Cronbach's alpha was 0.88 . The questionnaire consists of 51 items, and the total score of medication side effects were classified into five categories.

Severity of symptoms was measured using Symptom Severity scale of the Diagnostic and Statistical Manual of Mental Disorder 5th edition (SS-DSM5). The SS-DSM5 was developed by Ritsner et al. (2013), and further developed by the researcher. The reliability and internal consistency of the SS-DSM5 total score of the Cronbach's alpha was $>0.70$. The reliability of the SS-DSM5 in this study was tested using 30 schizophrenia patients, and the Cronbach's alpha was 0.76. The SS-DSM5 consists of 6 items with a five point scale ranging from $0=$ not present, $1=$ equivocal, $2=$ present, but mild ; $3=$ present and moderate, to $4=$ present and severe. The participants were asked to answer the severity of symptoms questionnaire based on their experience in the previous month. The scores of all items were classified by mean score, and scores more than or equal to 2 were considered to have sufficient severity.

\section{B. Data Collection}

Approval to conduct this study was achieved from the Ethical Review Board (ERB) committee of Boromarajonani College of Nursing Nopparat Vajira (BCNNV-Bangkok Thailand) with the approval number (ERB) No.18/2558, and obtained a permission letter from the West Java Province Mental Hospital, Indonesia. The eligible participants who willing to participate in this study were signed the informed consent. A number of 91 participants were met the inclusion criteria. Finally, 88 participants were completed self-administered questionnaire, and face-to-face interview. Data was collected from October to November 2015 at the outpatient department of West Java Province Mental Hospital, Indonesia.

\section{Data Analysis}

SPSS version 22.0 software was used to analyze the data. Approaches to data analysis included descriptive statistics: frequency, percentage, mean and standard deviation. Chisquare test were employed to assess the relationships between independent variables and medication adherence.

\section{Results}

A total of 88 self-administered questionnaires were distributed to patients with schizophrenia aged between 1859 years old at the outpatient department in the West Java 
Mental Hospital, West Java, Indonesia. In this study, 64.8\% of the participants were in adherence to their medication. Males constituted $79.5 \%$ of the subjects, and majority of the participants were employed with $67.0 \%$. More than half of the participants were single with $60.2 \%$, and aged $<40$ years with $68.2 \%$. More than one-third of the participants had average and low levels of medication side effects, equal with $39.8 \%$. However, only $2.3 \%$ of the participants had very high levels of medication side effects. In this study, $96.6 \%$ of the participants had not sufficient severity of symptoms.

TABLE 1. NUMBER OF PARTICIPANT AND PERCENTAGE OF SOCIOECONOMIC FACTORS $(\mathrm{n}=88)$

\begin{tabular}{|l|c|c|}
\hline Socioeconomic Factors & Number (n) & Percentage (\%) \\
\hline Gender & \multicolumn{2}{|l|}{} \\
\hline Male & 70 & 79.5 \\
\hline Female & 18 & 20.5 \\
\hline Age (years) & \multicolumn{2}{l|}{} \\
\hline$<40$ years & 60 & 68.2 \\
\hline$\geq 40$ years & 28 & 31.8 \\
\hline Marital Status & 35 & 60.2 \\
\hline Married & 53 & 33.0 \\
\hline Single & & 67.0 \\
\hline Employment Status & 59 & \\
\hline Unemployed & & \\
\hline Employed &
\end{tabular}

On bivariate analysis, the variables that are significantly associated with medication adherence include medication side effects $\left(\chi^{2}=8.417, \mathrm{p}<0.01\right)$, and severity of symptoms $\left(\chi^{2}=5.771, \mathrm{p}<0.05\right)$. Age, gender, marital status, and employment status did not show a significant association with medication adherence.

TABLE 2. CORRELATION BETWEEN INDEPENDENT VARIABLES AND MEDICATION ADHERENCE $(\mathrm{n}=88)$

\begin{tabular}{|c|c|c|c|c|}
\hline \multirow{3}{*}{ Variables } & \multicolumn{2}{|c|}{ Medication Adherence } & \multirow{3}{*}{$\chi^{2}$} & \multirow{3}{*}{$\begin{array}{c}P \text { - } \\
\text { value }\end{array}$} \\
\hline & Adherence & $\begin{array}{c}\text { Non- } \\
\text { Adherence }\end{array}$ & & \\
\hline & $\mathrm{n}(\%)$ & $\mathrm{n}(\%)$ & & \\
\hline \multicolumn{3}{|l|}{ Age } & \multirow{3}{*}{0.797} & \multirow{3}{*}{0.372} \\
\hline$<40$ years & $37(61.7 \%)$ & $23(38.3 \%)$ & & \\
\hline$\geq 40$ years & $20(71.4 \%)$ & $8(28.6 \%)$ & & \\
\hline \multicolumn{3}{|l|}{ Gender } & \multirow{3}{*}{0.550} & \multirow{3}{*}{0.428} \\
\hline Male & $44(62.9 \%)$ & $26(37.1 \%)$ & & \\
\hline Female & $13(72.2 \%)$ & $5(27.8 \%)$ & & \\
\hline \multicolumn{3}{|l|}{ Marital status } & \multirow{2}{*}{0.580} & \multirow{2}{*}{0.446} \\
\hline Married & $21(60.0 \%)$ & $14(40.0 \%)$ & & \\
\hline
\end{tabular}

\begin{tabular}{|c|c|c|c|c|}
\hline \multirow{3}{*}{ Variables } & \multicolumn{2}{|c|}{ Medication Adherence } & \multirow{4}{*}{$\chi^{2}$} & \multirow{4}{*}{$\begin{array}{c}P \text { P- } \\
\text { value }\end{array}$} \\
\hline & Adherence & $\begin{array}{c}\text { Non- } \\
\text { Adherence }\end{array}$ & & \\
\hline & $\mathrm{n}(\%)$ & $\mathrm{n}(\%)$ & & \\
\hline Single & $36(67.9 \%)$ & $17(32.1 \%)$ & & \\
\hline \multicolumn{3}{|c|}{ Employment status } & \multirow{3}{*}{0.139} & \multirow{3}{*}{0.710} \\
\hline Employed & $39(66.1 \%)$ & $20(33.9 \%)$ & & \\
\hline Unemployed & $18(62.1 \%)$ & $11(37.9 \%)$ & & \\
\hline \multicolumn{3}{|c|}{ Medication side effects } & \multirow{3}{*}{8.417} & \multirow{3}{*}{0.004} \\
\hline High & $22(50.0 \%)$ & $22(50.0 \%)$ & & \\
\hline Low & $35(79.5 \%)$ & $9(20.5 \%)$ & & \\
\hline \multicolumn{3}{|c|}{ Severity of symptoms } & \multirow{3}{*}{5.711} & \multirow{3}{*}{0.017} \\
\hline Sufficient & $0(0.0 \%)$ & $3(100.0 \%)$ & & \\
\hline $\begin{array}{l}\text { Not } \\
\text { sufficient }\end{array}$ & $57(67.1 \%)$ & $28(32.9 \%)$ & & \\
\hline
\end{tabular}

\section{Discussion}

The prevalence of medication adherence in this study was $64.8 \%$, indicating that the majority of the participants were in adherence with their medication. This finding was higher than the adherence rates reported in Taiwan, 50\% [11]; South Nigeria, $48.3 \%$ [6]. The variations in the reported rates of adherence between these studies could be explained by the differences in assessing medication adherence methods. In this study, socio-economics variables of the participants had no significant impact on medication adherence. In previous studies, socio-economic factors have been consistently associated with medication adherence. The results of study were supported by previous findings that there is no significant relationship of medication adherence with age [25], gender [21], marital status [6], and employment status [18].

Medication side effects were found as one of the factors related to medication adherence among patients with schizophrenia. The patients who had low or little of medication side effects were more adherent to their medication than patients who had high or a lot of medication side effects. This finding was congruent with the study of Bressington et al. (2013), which showed side effects of antipsychotic (difficulty concentrating, sleeping too much) were higher in the non-adherent patients than the adherent patients. This finding was also supported by several studies, reporting that the medication side effects were a significant factor that affect medication adherence in patients with schizophrenia [8], [28]. The patients with schizophrenia might have experienced side effects of antipsychotic medication ranging from mild discomfort to permanent movement disorder [15]. In this study, the participants mentioned having experience with the side effects of antipsychotics like sleeping too much, nausea, dizziness, tiredness, difficulty concentrating, and remembering things. The results of study showed almost half of the participants 
stated that their medication caused tiredness and sluggishness, and sometimes they stopped taking medicine when they felt worse while consuming it. For the majority of participants in this study who were employed, side effects of antipsychotic would lead to uncomfortable conditions during working. Furthermore, all these adverse effects of antipsychotics could influence patients on their level of adherence. This finding was in accordance with Videback (2014) who disclosed that side effects of antipsychotics are frightening and upsetting to clients, and they are frequently cited as the primary reason that the clients discontinue or reduce the dosage of their medication.

Severity of symptoms had statistically significant association with medication adherence. The patients who did not have sufficient severity of symptoms were more likely to have adherence to their medication than patients who had sufficient severity of symptoms. A study by Lam et al. (2013) on 82 stable patients with schizophrenia also described that non-adherence was more common in patients with more severe symptoms. This finding was supported by several studies that showed the severity of symptoms has significant association with medication adherence [13], [30], [38]. Adherence to medication has an important role to decrease the psychotic symptoms in patients with schizophrenia. In this study, common symptoms experienced by participants were hallucination. When the patients hallucinated, their thoughts did not function well. They might be not able to correctly identify the medicines, or they may believe the medicines are not necessary or even perhaps they hear some voices whispering to them to throw away the medicines. When the symptoms are present such as avolition, it could be lead them to do nothing, because they do not have enough motivation in their life. They will be more passive and have no enthusiasm for daily activities, including taking medication.

\section{v. Conclusion}

The health care providers should provide clear information to patients and caregivers regarding common side effects of antipsychotics. Enhance the ability of caregivers to identify symptoms of schizophrenia in order to improve patients' health status and reduce relapse.

\section{Limitations}

Self-administered questionnaire might be biased, when compared to objective measures of medication adherence such as pill count, electronic monitor, plasma concentrations, and pharmacy records, especially from individuals with severe mental illnesses whose answers might be affected by memory deficits, and levels of psychosis. The purposive sampling technique was used to select the participants, so the results of this study may not apply to the general population. The results may not be completely accurate, since the sample is small and consists mostly of males, with $79.5 \%$ of the total sample population.

\section{Acknowledgment}

This study was supported by the Directorate General of Higher Education (DGHE), Ministry of Research, Technology, and Higher Education of the Republic of Indonesia.

\section{References}

[1] Atreja, A., N. Bellam and S.R. Levy. 2005. Strategies to Enhance Patient Adherence: Making It Simple. Medscape General Medicine, 7(1), pp. 4-4.

[2] Bressington, D., J. Mui and R. Gray. 2013. Factors Associated with Antipsychotic Medication Adherence in Community-Based Patients with Schizophrenia in Hong Kong: A Cross Sectional Study. International Journal of Mental Health Nursing, 22(1), pp. 35-46.

[3] Brown, M.T. and J.K. Bussell. 2011. Medication Adherence: Who Cares? Mayo Clinic Proceedings. 86(4), pp. 304-314.

[4] Day, J.C., G. Wood, M. Dewey and R.P. Bentall. 1995. A SelfRating Scale for Measuring Neuroleptic Side-Effects. Validation in a Group of Schizophrenic Patients. The British Journal of Psychiatry, 166 (5), pp. 650-653.

[5] Dolder, C.R., J.P. Lacro, L.B. Dunn and D.V. Jeste. 2002. Antipsychotic Medication Adherence: Is There a Difference between Typical and Atypical Agents? American Journal of Psychiatry, 159 (1), pp. 103-108.

[6] Effiong, J.H. and K.A. Umoh. 2015. Medication Non Adherence in Schizophrenia: Prevalence and Correlates among Outpatients in a Tertiary Healthcare Facility in Uyo, South-South Nigeria, pp. 107113.

[7] Endale Gurmu, A., E. Abdela, B. Allele, E. Cheru and B. Amogne. 2014. Rate of Nonadherence to Antipsychotic Medications and Factors Leading to Nonadherence among Psychiatric Patients in Gondar University Hospital, Northwest Ethiopia. Advances in Psychiatry, pp.5.

[8] Eticha, T., A. Teklu, D. Ali, G. Solomon and A. Alemayehu. 2015. Factors Associated with Medication Adherence among Patients with Schizophrenia in Mekelle, Northern Ethiopia. PLoS ONE, vol 10(3).

[9] Gilbert, P.L., M. Harris, L. McAdams and D.V. Jeste. 1995. Neuroleptic Withdrawal in Schizophrenic Patients: A Review of the Literature. Archives of General Psychiatry, 52(3), pp. 173-188.

[10] Higashi, K., G. Medic, K.J. Littlewood, T. Diez, O. Granström and M. De Hert. 2013. Medication Adherence in Schizophrenia: Factors Influencing Adherence and Consequences of Nonadherence, a Systematic Literature Review. Therapeutic Advances in Psychopharmacology, 3(4), pp. 200-218.

[11] Huang, W.-F., J.-S. Cheng, I.-C.n. Lai and C.-F.H. eh. 2009. Medication Compliance in Outpatients with Schizophrenia in One Veterans Hospital in Taiwan, vol. 17, pp. 401-407.

[12] Janca, A., M. Kastrup, H. Katschnig, J.J. Lopez-Ibor, Jr., J.E. Mezzich and N. Sartorius. 1996. The World Health Organization Short Disability Assessment Schedule (Who Das-S): A Tool for the Assessment of Difficulties in Selected Areas of Functioning of Patients with Mental Disorders. Soc Psychiatry Psychiatr Epidemiol, 31(6), pp. 349-354.

[13] Jeste, S.D., T.L. Patterson, B.W. Palmer, C.R. Dolder, S. Goldman and D.V. Jeste. 2003. Cognitive Predictors of Medication Adherence among Middle-Aged and Older Outpatients with Schizophrenia. Schizophrenia Research, 63(1-2), pp. 49-58.

[14] Jungbauer, J., B. Wittmund, S. Dietrich and M.C. Angermeyer. 2004. The Disregarded Caregivers: Subjective Burden in Spouses of Schizophrenia Patients. Schizophrenia Bulletin, 30(3), pp. 665-675.

[15] Kane, J.M. and C.U. Correll. 2010. Pharmacologic Treatment of Schizophrenia. Dialogues in Clinical Neuroscience, 12(3), pp. 345357.

[16] Lacro, J.P., L.B. Dunn, C.R. Dolder, S.G. Leckband and D.V. Jeste. 2002. Prevalence of and Risk Factors for Medication Nonadherence 
in Patients with Schizophrenia: A Comprehensive Review of Recent Literature. The Journal of Clinical Psychiatry, 63(10), pp. 892-909.

[17] Lam, J.W., S.S. Lui, Y. Wang, R.C. Chan and E.F. Cheung. 2013. Prospective Memory Predicts Medication Management Ability and Correlates with Non-Adherence to Medications in Individuals with Clinically Stable Schizophrenia. Schizophrenia Research, 147(2-3), pp. 293-300.

[18] Lama, S., K.V. Lakshmi, P.M. Shyangwa and P. Parajuli. 2012. Level of Compliance and Factors Associated with Non-Compliance to Treatment among the Mentally Ill Patients. Nepal Journals OnLine, Volume 10(2).

[19] Leucht, S. and S. Heres. 2006. Epidemiology, Clinical Consequences, and Psychosocial Treatment of Nonadherence in Schizophrenia. The Journal of Clinical Psychiatry, 67 (5), pp. 3-8.

[20] Lindenmayer, J.P., H. Liu-Seifert, P.M. Kulkarni, B.J. Kinon, V. Stauffer, S.E. Edwards, L. Chen, D.H. Adams, H. Ascher-Svanum, P.F. Buckley, L. Citrome and J. Volavka. 2009. Medication Nonadherence and Treatment Outcome in Patients with Schizophrenia or Schizoaffective Disorder with Suboptimal Prior Response. Journal of Clinical Psychiatry, 70(7), pp. 990-996.

[21] Liu-Seifert, H., O.O. Osuntokun and P.D. Feldman. 2012. Factors Associated with Adherence to Treatment with Olanzapine and Other Atypical Antipsychotic Medications in Patients with Schizophrenia. Comprrehensive Psychiatry, 53(1), pp. 107-115.

[22] McCabe, R., J. Bullenkamp, L. Hansson, C. Lauber, R. MartinezLeal, W. Rossler, H.J. Salize, B. Svensson, F. Torres-Gonzalez, R. van den Brink, D. Wiersma and S. Priebe. 2012. The Therapeutic Relationship and Adherence to Antipsychotic Medication in Schizophrenia. PLoS ONE, vol. 7(4).

[23] McCann, T.V., E. Clark and S. Lu. 2009. Subjective Side Effects of Antipsychotics and Medication Adherence in People with Schizophrenia. Journal of Advance Nursing, 65(3), pp. 534-543.

[24] Ministry of Health of the Republic of Indonesia. 2013. Basic Health Research 2013 (Riset Kesehatan Dasar 2013). Available Source: http://depkes.go.id/downloads/riskesdas2013/Hasil\%20Riskesdas\%20 2013.pdf, April 17, 2015.

[25] Misdrahi, D., M. Petit, O. Blanc, F. Bayle and P.M. Llorca. 2012 The Influence of Therapeutic Alliance and Insight on Medication Adherence in Schizophrenia. Nordic Journal of Psychiatry, 66(1), pp. 49-54.

[26] Nursing Department of West Java Province Mental Hospital. 2014. Annual Report. West Java Province Mental Hospital. (Cisarua).

[27] Osterberg, L. and T. Blaschke. 2005. Adherence to Medication. New England Journal of Medicine, 353(5), pp. 487-497.

[28] Rettenbacher, M.A., A. Hofer, U. Eder, M. Hummer, G. Kemmler, E.M. Weiss and W.W. Fleischhacker. 2004. Compliance in Schizophrenia: Psychopathology, Side Effects, and Patients' Attitudes toward the Illness and Medication. The Journal of Clinical Psychiatry, 65(9), pp. 1211-1218.

[29] Ritsner, M.S., M. Mar, M. Arbitman and A. Grinshpoon. 2013. Symptom Severity Scale of the Dsm5 for Schizophrenia, and Other Psychotic Disorders: Diagnostic Validity and Clinical Feasibility. Psychiatry Research, 208(1), pp. 1-8.

[30] Tattan, T.M.G. and F.H. Creed. 2001. Negative Symptoms of Schizophrenia and Compliance with Medication. Schizophrenia Bulletin, 27(1), pp. 149-155.

[31] Thompson, K., J. Kulkarni and A.A. Sergejew. 2000. Reliability and Validity of a New Medication Adherence Rating Scale (Mars) for the Psychoses. Schizophria Research, 42(3), pp. 241-247.

[32] Vassileva, I.V. and V.K. Milanova. 2012. Attitudes toward Antipsychotic Medication, Insight and Psychopathology in Outpatients with Schizophrenia. Folia Medica, 54(4), pp. 62-68.

[33] Videback, S.L. 2014. Psychiatric-Mental Health Nursing. Lippincott William \& Wilkins, Philadelphia.

[34] Weiden, P.J. and M. Olfson. 1995. Cost of Relapse in Schizophrenia. Schizophrenia Bulletin, 21(3), pp. 419-429.

[35] World Health Organization. 2003. Adherence to Long-Term Therapies. Evidence for Action. Available Source: http://whqlibdoc.who.int/publications/2003/9241545992.pdf, 20 March 2015.

[36] World Health Organization. 2008. The Global Burden of Disease: 2004 Update. Available Source:
http://www.who.int/healthinfo/global_burden_disease/GBD_report_2 004update_full.pdf, 11 April 2015.

[37] World Health Organization. 2014. Statistic of Schizophrenia. Available Source: http://www.who.int/mental_health/management/schizophrenia/en/, 8 February 2015.

[38] Yang, J., Y.H. Ko, J.W. Paik, M.S. Lee, C. Han, S.H. Joe, I.K. Jung, H.G. Jung and S.H. Kim. 2012. Symptom Severity and Attitudes toward Medication: Impacts on Adherence in Outpatients with Schizophrenia. Schizophrenia Research, 134(2-3), pp. 226-231. 